\title{
A comparison of full profile prediction methods for a spudcan penetrating sand overlying clay
}

\author{
P. HU*, S. A. STANIER* ${ }^{*}$ D. WANG* and M. J. CASSIDY*
}

\begin{abstract}
Spudcans are the traditional footings used for offshore mobile jack-up rigs. However, the installation of spudcans in sand overlying clay may lead to punch-through failure, which can cause serious damage to the jack-up rig and endanger personnel. This article compares three new methods proposed in the literature and an interpretation of the International Organization for Standardization (ISO) guideline for predicting the full penetration resistance profile. The penetration resistance profile for each of the methods is characterised by two key calculations: the peak resistance in the sand and the bearing capacity within the underlying clay. The punch-through distance - an indicator of the potential for and severity of punch-through failure - is estimated from these calculations. In comparison with 71 geotechnical centrifuge tests, the ISO guideline provides poor predictions, consistently underestimating the peak resistance in the sand and the underlying bearing capacity in the clay. Although all three of the new methods provide a superior response, by assessing the accuracy, scatter and geometric skew of the predictions, two of the methods are shown to be biased in at least one of the key calculations used to define the penetration resistance profile, thus producing bias in the prediction of the punch-through distance. However, one method yields largely unbiased predictions.
\end{abstract}

KEYWORDS: bearing capacity; centrifuge modelling; footings/foundations; offshore engineering

ICE Publishing: all rights reserved

NOTATION

$A$ widest cross-sectional area of spudcan

$D$ diameter of spudcan

$D_{\mathrm{F}}$ distribution factor

$d$ penetration depth of spudcan

$d_{\text {base }}$ depth from bottom of sand plug to sand-clay interface

$d_{\mathrm{c}}$ depth factor

$d_{\text {peak }}$ spudcan depth at peak penetration resistance

$d_{\text {punch }}$ punch-through distance

$d_{\text {punch,calculated }}$ calculated punch-through distance

$d_{\text {punch,measured }}$ measured punch-through distance

$d_{\mathrm{sb}} \quad$ depth from bottom of sand plug to soil surface

$E^{*} \quad$ parameter to simplify algebra

$H_{\text {eff }}$ distance between depth of peak resistance and sand-clay interface

$H_{\mathrm{fdn}}$ height of composite foundation of spudcan and sand plug

$H_{\text {plug }}$ sand plug height

$H_{\mathrm{s}}$ sand thickness

$h_{\mathrm{f}}$ thickness of spudcan at widest section

$I_{\mathrm{D}}$ relative density

$K_{\mathrm{p}}$ coefficient of passive earth pressure

$K_{\mathrm{s}}$ punching shear coefficient

$k$ strength gradient of clay

$N_{\mathrm{c}}$ bearing capacity factor

$N_{\mathrm{c} 0} \quad$ bearing capacity factor of clay at base level of a circular foundation

$N_{\mathrm{c}, \text { calculated }}$ calculated bearing capacity factor

Manuscript received 31 March 2015; first decision 7 May 2015; accepted 21 May 2015.

Published online at www.geotechniqueletters.com on 10 August 2015.

${ }^{*}$ Centre for Offshore Foundation Systems and ARC Centre of Excellence for Geotechnical Science and Engineering, The University of Western Australia, Crawley, WA, Australia
$N_{\mathrm{c}, \text { measured }}$ measured bearing capacity factor

$n_{\mathrm{s}}$ load spread factor

$Q_{\text {c,peak }}$ clay vertical bearing capacity subjected to vertical and inclined loadings within an area of radius $R$

$Q_{\text {s,peak }} \quad$ vertical component of shear force developed along a simplified inclined failure surface in the upper sand layer

$Q_{\mathrm{v}} \quad$ bearing capacity in clay

$q_{0}$ effective overburden pressure

$q_{\text {clay }}$ penetration resistance in the clay layer

$q_{\text {peak }}$ peak penetration resistance

$q_{\text {peak,calculated }}$ calculated peak penetration resistance

$q_{\text {peak,measured }}$ measured peak penetration resistance

$r$ geometric parameter

$s_{\mathrm{c}}$ shape factor

$s_{\mathrm{u}} \quad$ undrained shear strength of clay

$s_{\mathrm{u} 0}$ clay shear strength at lowest level of the spudcan widest cross-sectional area

$s_{\text {ua }} \quad$ average value of shear strength from $d-h_{\mathrm{f}}$ to $d+H_{\text {plug }}$

$s_{\mathrm{ub}} \quad$ shear strength of clay at base of composite foundation

$s_{\mathrm{um}}$ shear strength of clay at sand-clay interface

$V_{\mathrm{f}}$ volume of spudcan

$W_{\text {peak }}$ weight of sand wedge trapped between spudcan level and sand-clay interface

$\alpha_{\text {side }}$ side adhesion factor

$\gamma_{\mathrm{c}}^{\prime}$ effective unit weight of clay

$\gamma_{s}^{\prime}$ effective unit weight of sand

$\theta^{*} \quad$ skew angle

$\kappa$ dimensionless strength increasing parameter for non-homogeneous cohesive soils

$\sigma$ standard deviation

$\phi_{2}$ reduced operative friction angle

$\phi^{\prime} \quad$ friction angle of sand

$\phi^{*} \quad$ reduced friction angle due to non-associated flow rule

$\phi_{\mathrm{cv}}$ critical state friction angle of sand

$\psi \quad$ dilation angle of sand

$\omega$ geometric parameter 


\section{INTRODUCTION}

Offshore jack-ups typically consist of a buoyant triangular hull supported by three independent legs that are fitted with spudcan foundations (Fig. 1). Punch-through events can occur during installation in sand overlying clay when the sand layer yields, causing the spudcan to plunge into the underlying weaker clay. A large number of centrifuge model tests investigating punch-through in sand overlying clay have been reported (Lee, 2009; Teh et al., 2010; Lee et al., 2013a; Hu et al., 2014a; Hu, 2015). Retrospective predictions for this database of experiments are used to assess and compare punch-through predictions from the latest industry guidelines for the siteassessment of jack-ups (ISO, 2012) and three new methods, proposed by

- Teh (Teh, 2007)

- Lee et al. (Lee, 2009; Lee et al., 2013a, 2013b)

- Hu et al. (Hu et al., 2014a, 2014b; Hu, 2015).

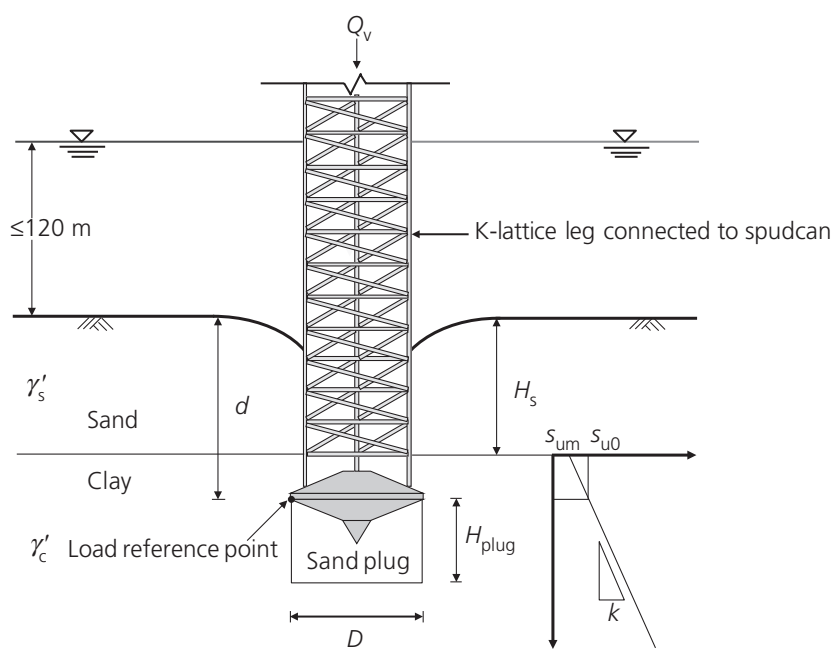

Fig. 1. Problem definition and notation
SIMPLIFIED FULL PROFILE PREDICTION

All four methods simplify the spudcan penetration profile (Fig. 2) as a combination of

- A, spigot embedment resistance

- B, peak resistance in the sand layer $q_{\text {peak }}$

- $\mathrm{C}$, resistance at the sand-clay interface and

- $\mathrm{D}$, resistance in the clay layer $q_{\text {clay }}$ where it is equal to $q_{\text {peak }}$.

The punch-through distance is assessed by calculating the depth over which $q_{\text {peak }}$ is greater than $q_{\text {clay }}$ Table 1 provides all of the design equations used to generate the predictions, with Figs 3 and 4 showing the basis of the calculations.

\section{Peak resistance}

In the method proposed by Teh, $q_{\text {peak }}$ is composed of the vertical component of the shearing resistance in the mobilised sand frustum, the bearing capacity of the underlying clay and the self-weight of the sand. However, the full bearing capacity of the underlying clay is assumed to act on a limited region from the centreline, beyond which the bearing capacity is assumed to reduce linearly to a minimum value of $0.5 q_{\text {clay }}$ (Fig. 3(a)).

The Lee et al. method assumes that $q_{\text {peak }}$ occurs when a sand frustum with a dispersion angle equal to the mobilised dilation angle of the sand is pushed into the underlying clay; $q_{\text {peak }}$ is the sum of the frictional resistance in the sand, the bearing capacity of the underlying clay and the weight of the sand frustum (Fig. 3(b))

The $\mathrm{Hu}$ et al. method modifies the method of Lee et al. to account for the embedment depth attained during the mobilisation of $q_{\text {peak }}$ (Fig. 3(c)) and extends it to account for various spudcan geometries and sand densities. The relationship for a distribution factor $D_{\mathrm{F}}$ was optimised for the new mechanism, resulting in power relationships calibrated for both very dense and medium-dense sands and for footing conical angles from $0^{\circ}$ to $21^{\circ}$ ( Hu et al., 2014a; $\mathrm{Hu}, 2015)$.

In application of the three methods in this article, the depth of the peak resistance $d_{\text {peak }}$ is taken as $0 \cdot 12 H_{\mathrm{s}}$ (when $\left.0 \cdot 16 \leq H_{\mathrm{s}} / D \leq 1\right)$, where $H_{\mathrm{s}}$ is the sand layer thickness and

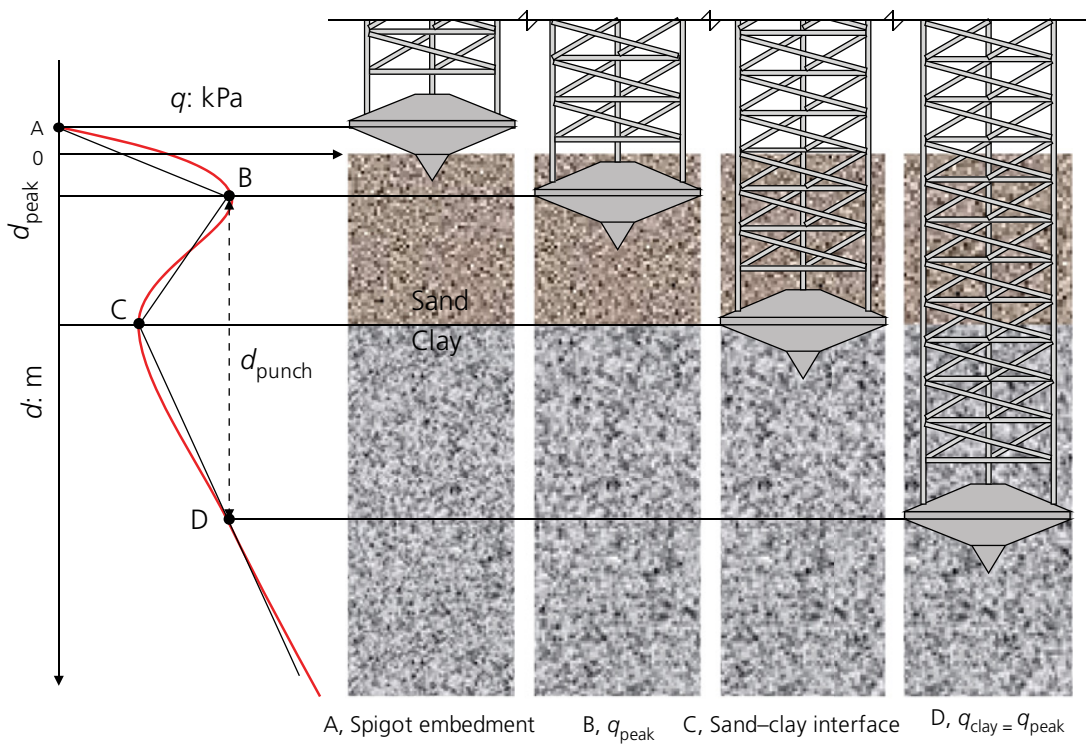

Fig. 2. Simplified spudcan penetration resistance profile prediction method 
Table 1. Full profile design equations for the Teh method, Lee et al. method, ISO methods and Hu et al. method

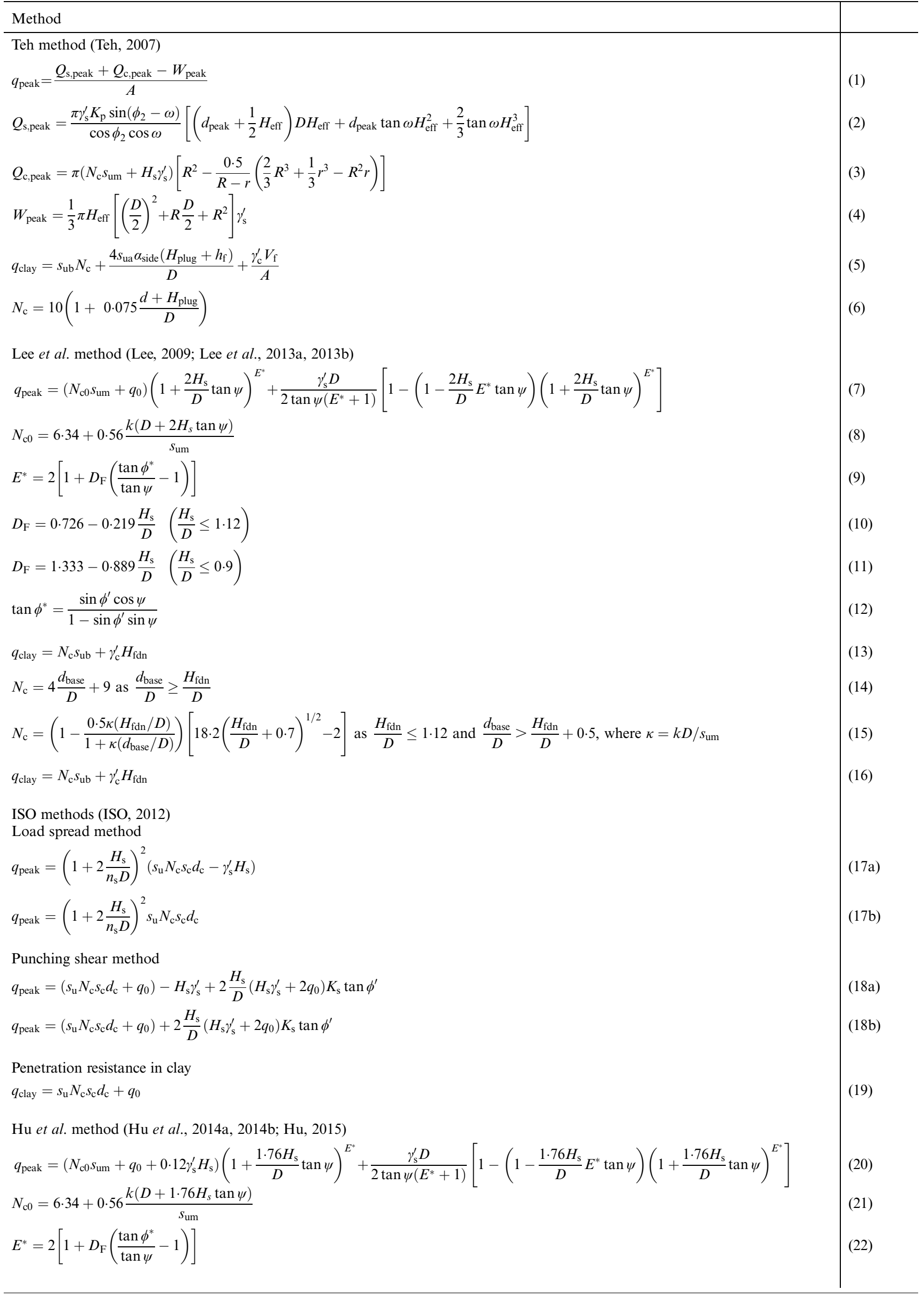


Table 1 Continued

\begin{tabular}{|c|c|}
\hline Method & \\
\hline$D_{\mathrm{F}}=0.642\left(\frac{H_{\mathrm{s}}}{D}\right)^{-0.576}$ as $0.16 \leq \frac{H_{\mathrm{s}}}{D} \leq 1.0$ & (23) \\
\hline$D_{\mathrm{F}}=0.623\left(\frac{H_{\mathrm{s}}}{D}\right)^{-0.174}$ as $0.21 \leq \frac{H_{\mathrm{s}}}{D} \leq 1.12$ & (24) \\
\hline $\tan \phi^{*}=\frac{\sin \phi^{\prime} \cos \psi}{1-\sin \phi^{\prime} \sin \psi}$ & (25) \\
\hline$q_{\text {clay }}=N_{\mathrm{c}} s_{\mathrm{u} 0}+H_{\mathrm{plug}} \gamma_{\mathrm{c}}^{\prime}=N_{\mathrm{c}} s_{\mathrm{u} 0}+0 \cdot 9 H_{\mathrm{s}} \gamma_{\mathrm{c}}^{\prime}\left(0 \cdot 16 \leq \frac{H_{\mathrm{s}}}{D} \leq 1 \cdot 00\right)$ & (26) \\
\hline$N_{\mathrm{c}}=11 \frac{H_{\mathrm{s}}}{D}+10 \cdot 5\left(0 \cdot 16 \leq \frac{H_{\mathrm{s}}}{D} \leq 1 \cdot 12\right)$ & (27) \\
\hline
\end{tabular}

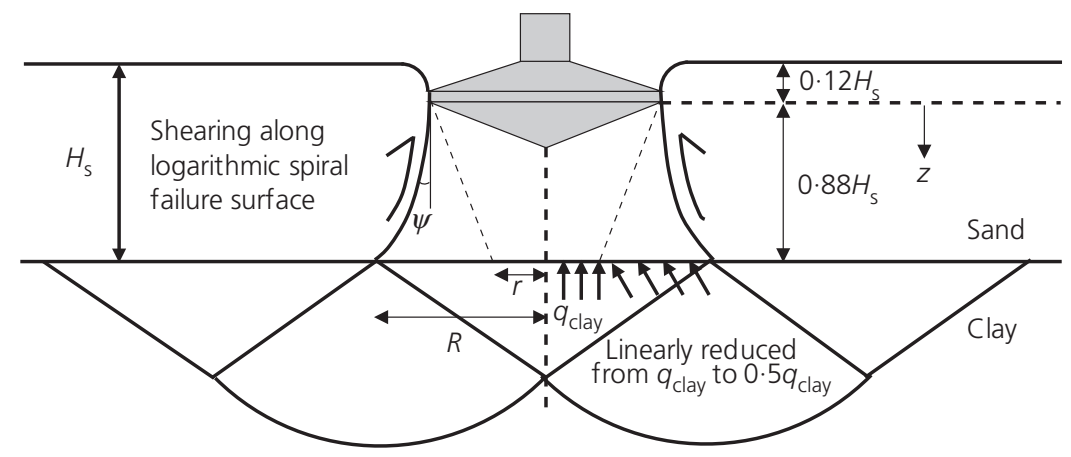

(a) Teh method

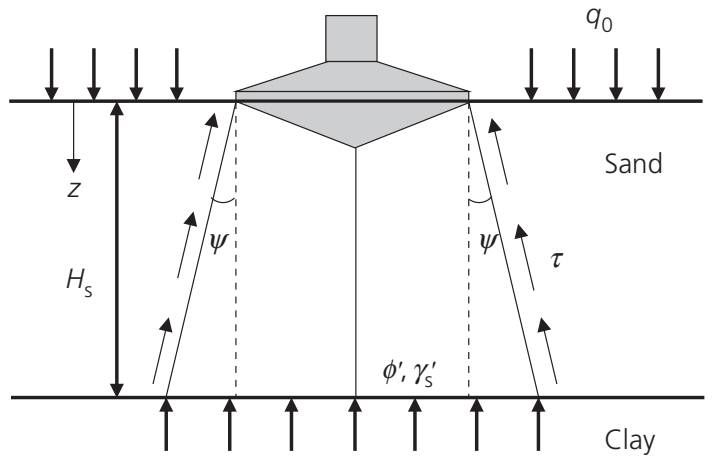

$q_{\text {clay }}$

(b) Lee et al. method

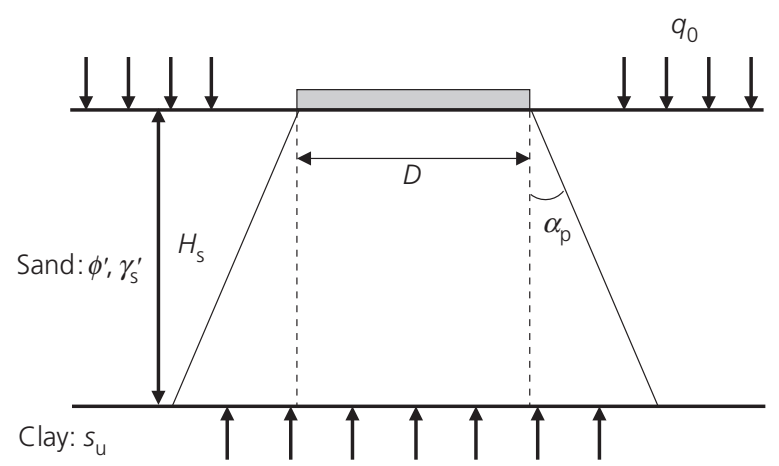

$s_{c} N_{c} s_{u}+q_{0}\left(+\gamma_{s}^{\prime} H_{s}\right)$

(d) Load spread method

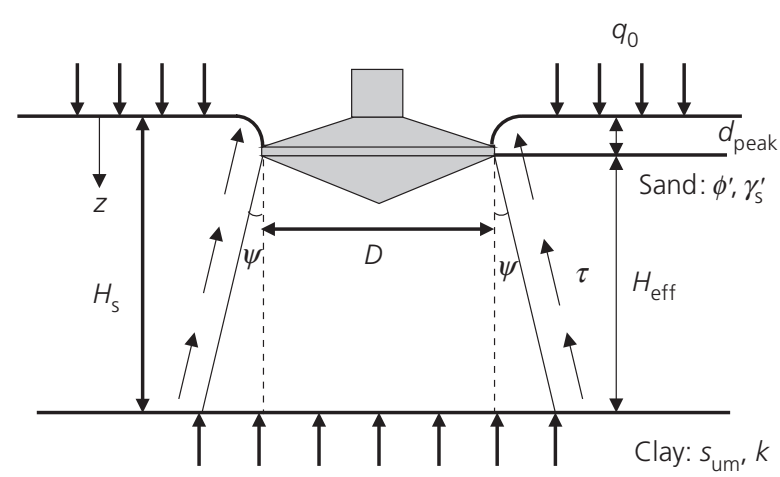

$q_{\text {clay }}$

(c) Hu et al. method

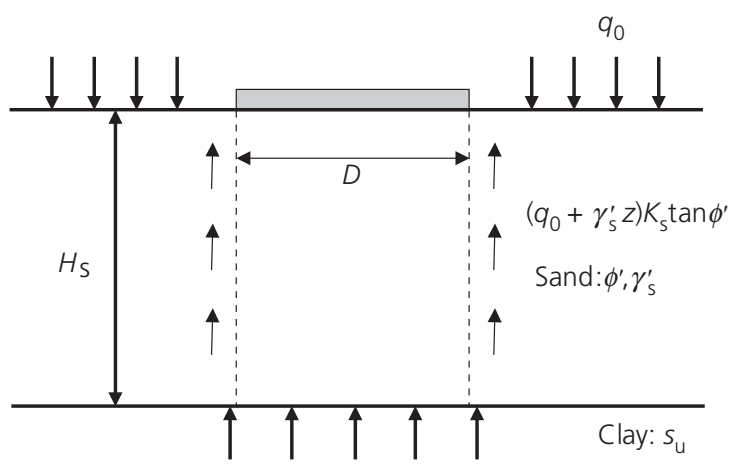

$s_{\mathrm{c}} N_{\mathrm{c}} s_{\mathrm{u}}+q_{0}\left(+\gamma_{\mathrm{s}}^{\prime} H_{\mathrm{s}}\right)$

(e) Punching shear method

Fig. 3. Conceptual models for peak resistance from methods of (a) Teh, (b) Lee et al., (c) Hu et al., (d) load spread method of ISO and (e) punching shear method of ISO 


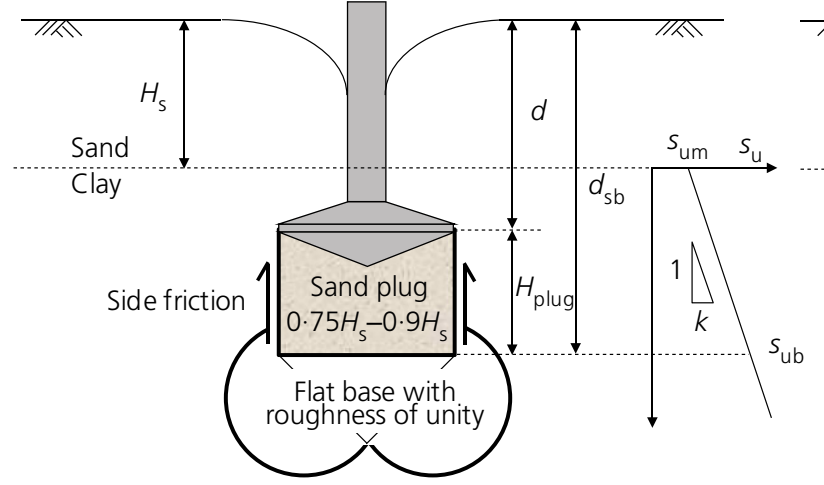

(a) Teh method

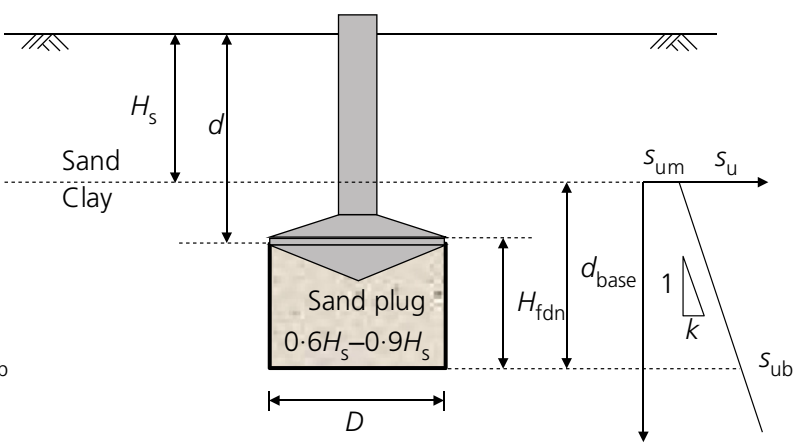

(b) Lee et al. method

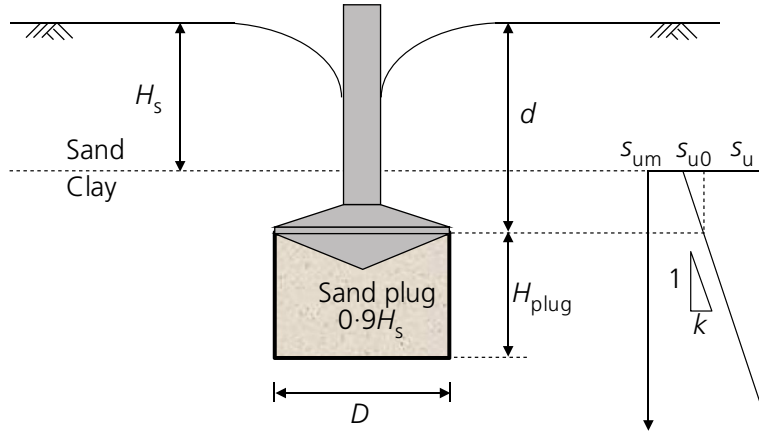

(c) Hu et al. method

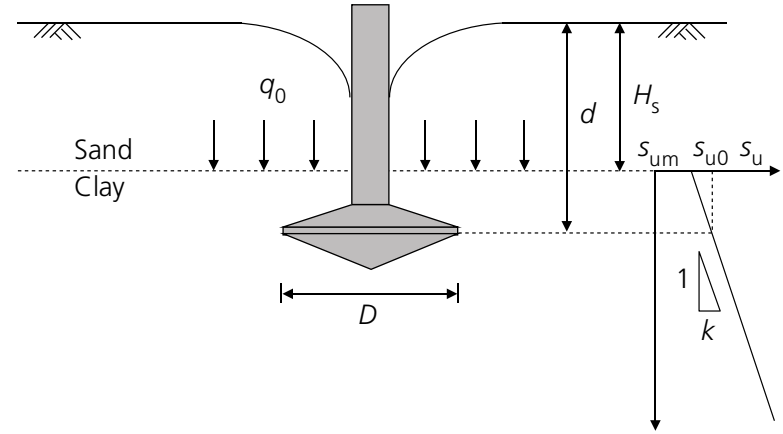

(d) ISO method

Fig. 4. Nomenclature of soil bearing capacity in underlying clay for methods of (a) Teh, (b) Lee et al., (c) Hu et al. and (d) ISO

Table 2. Summary of sand overlying clay centrifuge tests reported in the literature

\begin{tabular}{|c|c|c|c|c|c|c|c|}
\hline & $\begin{array}{l}\text { Lee (2009) } \\
\text { UWA tests }\end{array}$ & $\begin{array}{l}\text { Teh et al. } \\
(2010) \\
\text { NUS tests }\end{array}$ & $\begin{array}{l}\text { Teh et al. } \\
(2010) \\
\text { UWA tests }\end{array}$ & $\begin{array}{l}\text { Lee } \text { et al. } \\
\text { (2013a) } \\
\text { UWA tests }\end{array}$ & $\begin{array}{l}\text { Hu et al. } \\
(2014 \mathrm{a}) \\
\text { UWA tests }\end{array}$ & $\begin{array}{l}\mathrm{Hu}(2015) \\
\text { UWA tests }\end{array}$ & Summary \\
\hline Centrifuge type & Beam & Beam & Beam & Drum & Drum & Drum & Beam/drum \\
\hline Number of tests & 5 & & & 30 & 15 & 11 & 71 \\
\hline Geometry & & & & & & & \\
\hline$D: \mathrm{m}$ & $8-14$ & 10 & $4-8$ & $6-16$ & $6-20$ & 8 & $4-20$ \\
\hline$H_{\mathrm{s}}: \mathrm{m}$ & & $3-10$ & $3 \cdot 5-7 \cdot 1$ & $3 \cdot 4-6 \cdot 7$ & $3 \cdot 2-6$ & $3 \cdot 03-7 \cdot 25$ & $3-10$ \\
\hline$H_{\mathrm{s}} / D$ & $0 \cdot 50-0 \cdot 88$ & $0 \cdot 3-1 \cdot 0$ & $0 \cdot 58-0.89$ & $0 \cdot 21-1 \cdot 12$ & $0 \cdot 16-1 \cdot 00$ & $0 \cdot 38-0 \cdot 91$ & $0 \cdot 16-1 \cdot 12$ \\
\hline $\begin{array}{l}\text { Conical angle: } \\
\text { degrees }\end{array}$ & 13 & 10 & 13 & $0-13$ & 13 & $0-21$ & $0-21$ \\
\hline Sand & & & & & & & \\
\hline$I_{\mathrm{D}}: \%$ & 99 & $58-95$ & 98-99 & 92 & 43 & 74 & 43-99 \\
\hline$\phi_{\mathrm{cv}}:$ degrees $^{\mathrm{a}}$ & 31 & & & 31 & 31 & 31 & $31-32$ \\
\hline $\begin{array}{l}\gamma_{\mathrm{s}}^{\prime}: \mathrm{kN} / \mathrm{m}^{3} \\
\text { Clay }^{\mathrm{b}}\end{array}$ & $11 \cdot 15$ & $9 \cdot 15-9 \cdot 93$ & $11 \cdot 13-11 \cdot 15$ & $10 \cdot 99$ & $9 \cdot 96$ & $10 \cdot 61$ & $9 \cdot 15-11 \cdot 15$ \\
\hline$s_{\text {um }}: \mathrm{kPa}$ & $13 \cdot 2$ & $7 \cdot 75-25 \cdot 82$ & $7 \cdot 22-14 \cdot 62$ & $16 \cdot 3-19 \cdot 1$ & $11 \cdot 01-12 \cdot 96$ & $11 \cdot 31-22 \cdot 24$ & $7 \cdot 22-25 \cdot 82$ \\
\hline$k: \mathrm{kPa} / \mathrm{m}$ & 1.85 & 1.56 & $1 \cdot 20$ & $2 \cdot 10$ & $1 \cdot 54-1 \cdot 55$ & $1 \cdot 51-2 \cdot 13$ & $1 \cdot 2-2 \cdot 13$ \\
\hline$\gamma_{\mathrm{c}}^{\prime}: \mathrm{kN} / \mathrm{m}^{3}$ & N/A & 6 & $6 \cdot 5$ & $7 \cdot 5$ & $7 \cdot 11$ & $7 \cdot 21$ & $6-7 \cdot 5$ \\
\hline$q_{\text {peak }}: \mathrm{kPa}$ & $421 \cdot 30-606 \cdot 48$ & $154 \cdot 78-699 \cdot 54$ & $270-608$ & $219-71$ & $169 \cdot 92-382 \cdot 95$ & $237 \cdot 28-758 \cdot 95$ & $154 \cdot 78-758 \cdot 95$ \\
\hline$d_{\text {punch }}: \mathrm{m}$ & N/A & $3 \cdot 93-7 \cdot 30$ & $9 \cdot 16-10 \cdot 33$ & $0 \cdot 20-12 \cdot 20$ & $5 \cdot 22-8 \cdot 10$ & $4 \cdot 75-13.94$ & $0 \cdot 20-13 \cdot 94$ \\
\hline
\end{tabular}

${ }^{\mathrm{a}} \phi_{\mathrm{cv}}$ is the critical state friction angle of sand

${ }^{\mathrm{b}}$ Kaolin clay was used in all the centrifuge tests

$D$ is the diameter of the spudcan. This is based on experimental observations of Teh et al. $(2008,2010)$ and $\mathrm{Hu}$ et al. (2014a).

ISO (2012) recommends both load spread and punching shear methods. For the load spread method (Fig. 3(d)), $q_{\text {peak }}$ is equated to the capacity of a fictitious footing of increased area at the sand-clay interface (a load spread ratio of 3 is used as it provides higher $q_{\text {peak }}$ predictions). However, there is ambiguity regarding the position of the surcharge during the calculation of the bearing capacity of the larger fictitious footing. The ISO guideline (figure A9.3-11 of ISO 19905.5 (ISO, 2012)) indicates that the effective overpressure at the footing level should be used in conjunction with the bearing capacity equation (equation A9-3-7). In this case, the pressure should remain as just $q_{0}$ when calculating the bearing capacity of the fictitious footing. However, the authors consider that the actual surcharge on the clay layer should be assumed. That is, the surcharge at the spudcan 


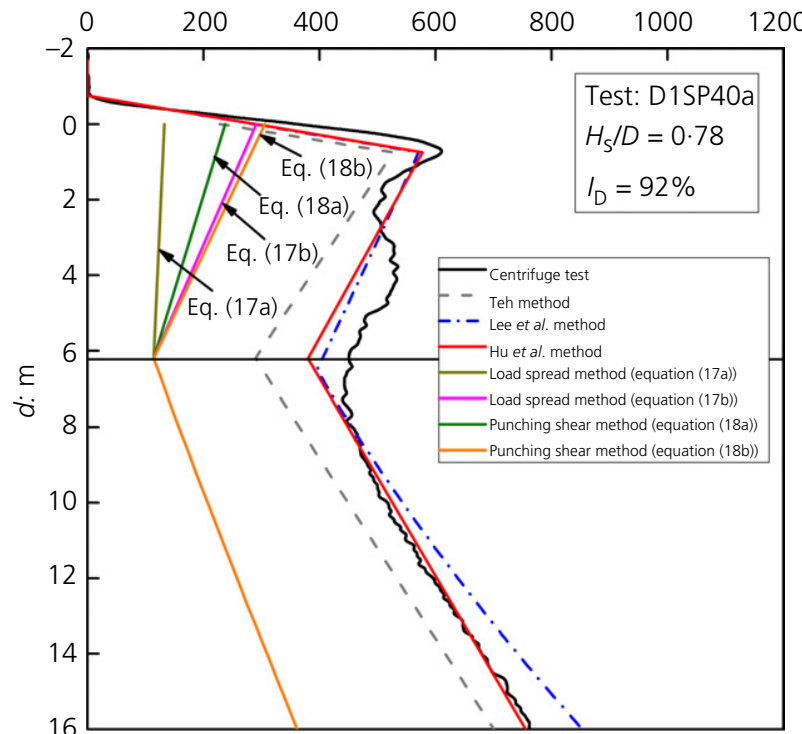

(a)

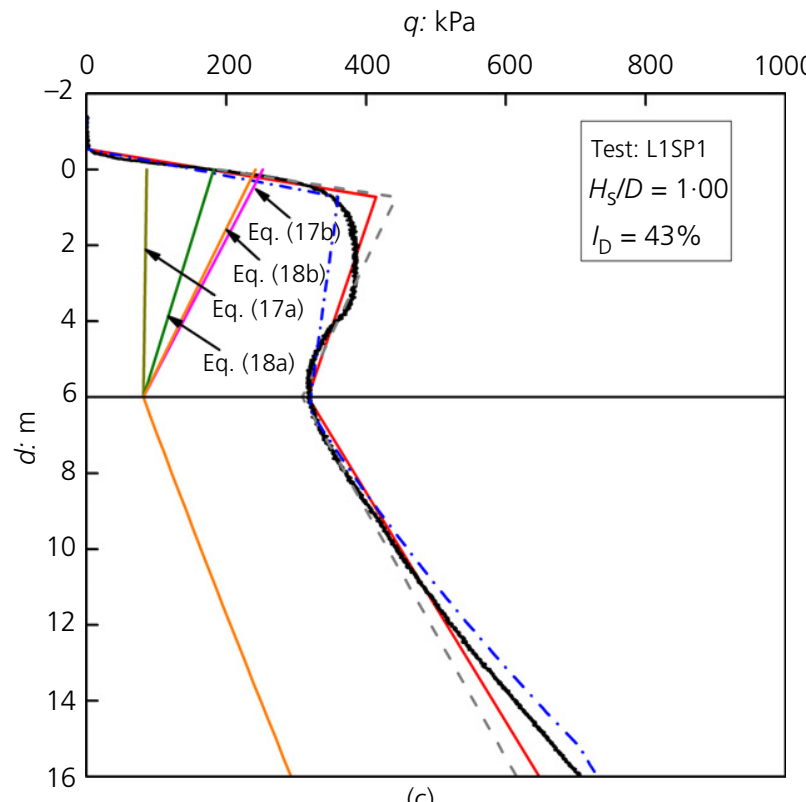

$q: \mathrm{kPa}$

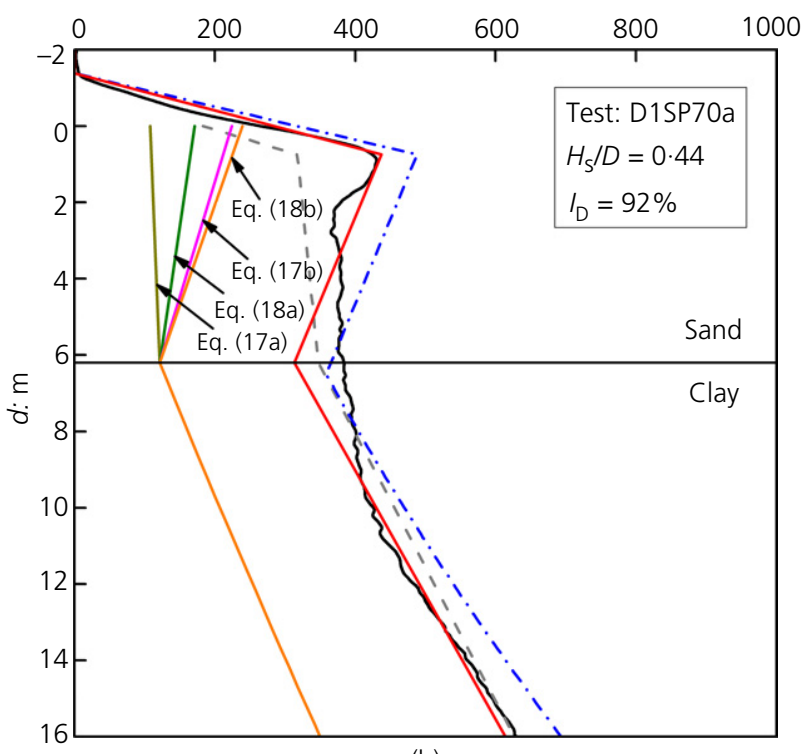

(b)

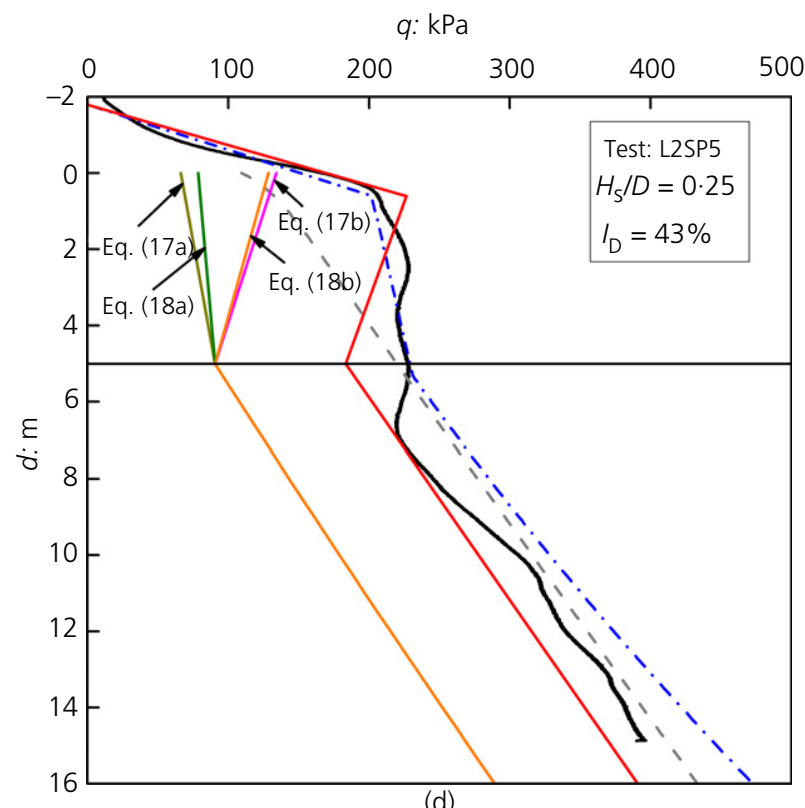

(d)

Fig. 5. Selected comparisons of experimentally measured punch-through profiles with all calculation methods

level $\left(q_{0}\right)$ should have an additional surcharge due to the sand layer between it and the fictitious footing added to it (i.e. $q_{0}+\gamma_{\mathrm{s}}^{\prime} H_{\mathrm{s}}$, where $\gamma_{\mathrm{s}}^{\prime}$ is submerged unit weight of sand). Both assumptions were used to retrospectively predict the experimental database (equations (17a) and (17b) in Table 1).

The punching shear method (Fig. 3(e)) of ISO (2012) assumes that a cylindrical frustum of sand is pushed into the underlying clay, mobilising frictional resistance on the vertical surface of the frustum and clay bearing capacity at the base. This method has the same ambiguity as the load spread method regarding the position of the surcharge and therefore both assumptions were calculated (equations (18a) and (18b) in Table 1).

\section{Clay resistance}

All methods use a form of the bearing capacity equation to calculate spudcan resistance in the underlying clay layer, though with differing interpretations of the bearing capacity factor $\left(N_{\mathrm{c}}\right)$ and the influence of the sand plug that has been shown to become trapped beneath the spudcan (Craig \& Chua, 1990; Teh et al., 2008; Lee et al., 2013a).

All three new methods assume that the entrapped sand plug is cylindrical in shape (Figs 4(a)-4(c)), though a range of sand plug heights from $0 \cdot 6 H_{\mathrm{s}}$ to $0 \cdot 9 H_{\mathrm{s}}$ was measured. A sand plug height of $0.9 H_{\mathrm{s}}$ was concluded from both fullspudcan and half-spudcan centrifuge tests and further validated by large-deformation finite-element $(\mathrm{FE})$ analyses in $\mathrm{Hu}$ (2015). To fairly compare the three methods, a value of $0 \cdot 9 H_{\mathrm{s}}$ was used in the retrospective predictions. ISO (2012) does not mention a sand plug and therefore none is assumed.

The Teh method uses the $N_{\mathrm{c}}$ factor derived by Hossain et al. (2006) for just a spudcan penetrating into a single clay layer. The Lee et al. method uses new $N_{\mathrm{c}}$ relations derived from small-strain FE analyses, accounting for the composite spudcan and sand plug. Alternatively, the $\mathrm{Hu}$ et al. method simplifies $N_{\mathrm{c}}$ by using an expression back-calculated from 


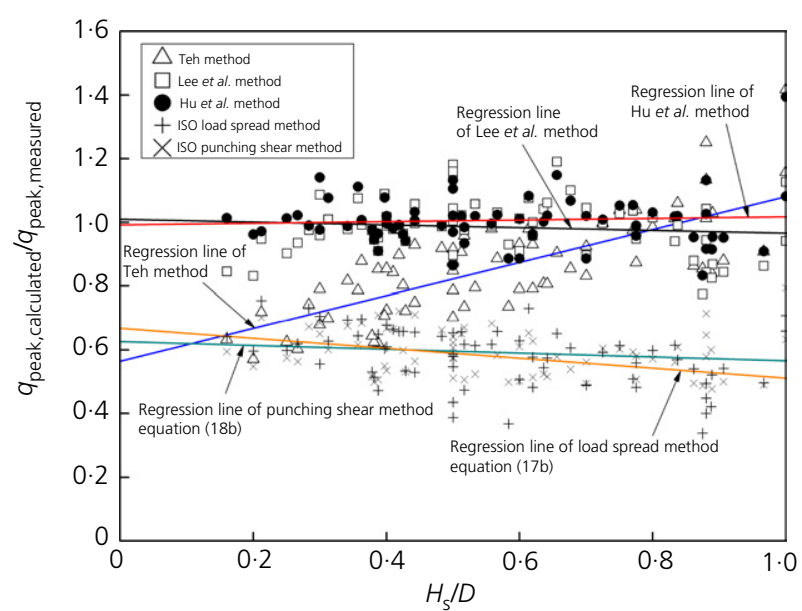

(a)

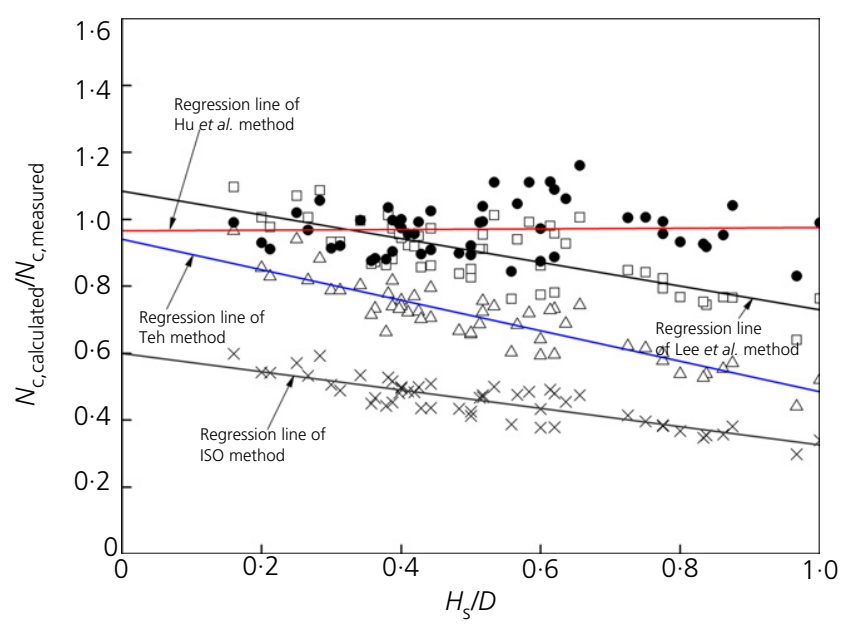

(b)

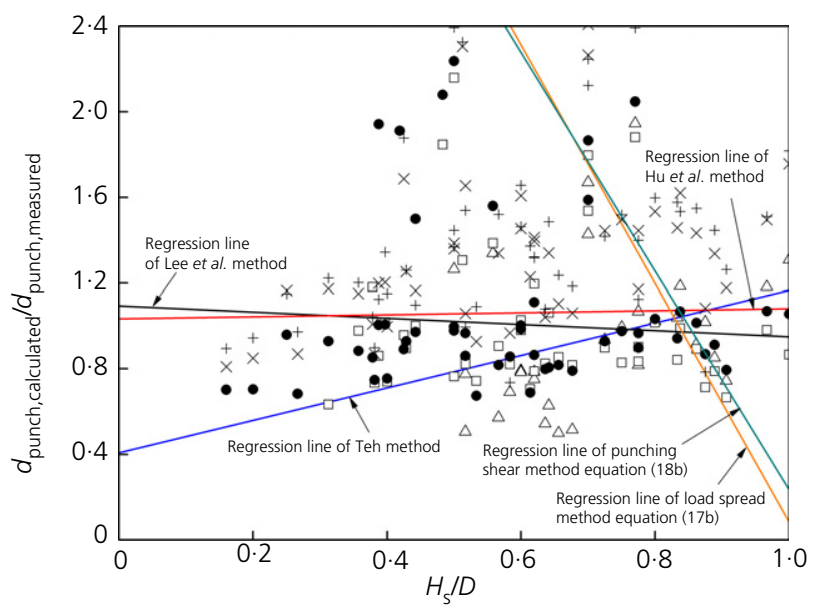

(c)

Fig. 6. Comparison of performance of calculation methods against centrifuge database: (a) peak penetration resistance $q_{\text {peak }}$; (b) bearing capacity factor $N_{c}$; (c) punch-through distance $d_{\text {punch }}$

large-deformation FE analyses of the full penetration process. The ISO guideline uses the expressions for $N_{\mathrm{c}}$ given in Houlsby \& Martin (2003), so those were adopted for the ISO predictions.

\section{COMPARISON AND DISCUSSION}

The 71 centrifuge tests contributing to the experimental database are detailed in Table 2. These cover the range of parameters and geometries typically encountered in the field. Punch-through was observed in 62 of the 71 tests.

\section{Full penetration resistance profile predictions}

The methods were evaluated using retrospective predictions of the centrifuge experiments. Four typical centrifuge tests two very dense sand tests (relative density $I_{\mathrm{D}}=92 \%$ ) from Lee et al. (2013a) and two medium-dense sand tests $\left(I_{\mathrm{D}}=\right.$ $43 \%$ ) from $\mathrm{Hu}$ et al. (2014a) - are first highlighted here to evaluate the performance of each method. All comparisons are available in the supplementary data.

As shown in Fig. 5, both $q_{\text {peak }}$ and $q_{\text {clay }}$ predicted by the Teh method deviate from those measured, and no punchthrough is predicted for some of the cases in which punchthrough was observed in the experiments. The Lee et al. method overestimates $q_{\text {clay }}$, which causes underestimation of the punch-through distance. Due to the adoption of the load spread method or the punching shear method for the calculation of $q_{\text {peak }}$ and the effect of the sand plug in the underlying clay layer being ignored, the ISO method underestimates the penetration resistances significantly. In contrast, the $\mathrm{Hu}$ et al. method displays better prediction of both $q_{\text {peak }}$ and $q_{\text {clay }}$, leading to better overall predictions of the penetration resistance and the punch-through distance.

\section{Comparisons of $q_{\text {peak }} N_{\mathrm{c}}$ and $d_{\text {punch }}$}

Comparisons of $q_{\text {peak }}, N_{\mathrm{c}}$ and $d_{\text {punch }}$ predicted using each method are presented in Fig. 6. Ratios of calculated to measured values for each of the measures are plotted against $H_{\mathrm{s}} / D$ and a linear regression line for each method is displayed to highlight the skew of the prediction. A statistical summary is provided in Table 3 .

For the ISO load spread and punching shear methods, the interpretation with the additional surcharge (equations (17b) and (18b)) was used in Fig. 6 as it was shown in Fig. 5 that it performs better. As shown in Fig. 6(a), both the load spread method and the punching shear method under-predict $q_{\text {peak }}$ significantly, with mean values of 0.58 and 0.59 , respectively. The load spread method could be made to fit the database by adjusting the spreading ratio $n_{\mathrm{s}}$ (see Table 1). Values required to fit the experimental data were back-calculated and are shown in Fig. 7 to fit the range $0.91 \leq n_{\mathrm{s}} \leq 2.07$, with a mean of 1.42. This is far smaller than the range between 3 and 5 recommended in the ISO guideline. Baglioni et al. (1982) suggested that the load dispersion angle in the load spread method is equal to the friction angle of sand, which is equivalent to $1.73 \leq n_{\mathrm{s}} \leq 2.75$ derived from tests on field soil samples. The range reported here is consistent with the above findings.

The Teh method provides a conservative prediction of $q_{\text {peak }}$, with $q_{\text {peak,calculated }} / q_{\text {peak,measured }}$ generally less than unity. The predicted $q_{\text {peak }}$ values might be as low as $40 \%$ of the experimental measurements. A large variation of the predictions is indicated by a high coefficient of variation $(\mathrm{CoV})$ of $18 \%$. The Lee et al. method yields a significantly improved prediction, with $q_{\text {peak,calculated }} / q_{\text {peak,measured }}$ between 0.77 and 1.28 , a mean value of 0.98 and a much-reduced $\mathrm{CoV}$ of $9 \cdot 4 \%$. However, both Fig. 6(a) and Table 3 indicate that mild bias exists with $H_{\mathrm{s}} / D$ with a skew angle of $-4 \cdot 01^{\circ}$. This is improved upon with the $\mathrm{Hu}$ et al. method, which provides reasonably good comparisons with $q_{\text {peak,calculated }} / q_{\text {peak,measured }}$ between 0.83 and $1 \cdot 39$, a mean value of 1.01 and the lowest scatter and skew of all the methods $\left(8 \cdot 2 \%\right.$ and $1 \cdot 47^{\circ}$, respectively).

Figure 6(b) shows that the adoption of $N_{\mathrm{c}}$ values for spudcan penetration in single-layer clay causes significant under-prediction of $N_{c}$ in the Teh and ISO methods, 
Table 3. Model performance indicators for each of the prediction methods

\begin{tabular}{|c|c|c|c|c|c|c|c|}
\hline & \multirow[t]{2}{*}{ Teh method } & \multirow{2}{*}{$\begin{array}{l}\text { Lee } \text { et al. } \\
\text { method }\end{array}$} & \multirow{2}{*}{$\begin{array}{l}\text { Hu et al. } \\
\text { method }\end{array}$} & \multicolumn{2}{|c|}{ ISO load spread method } & \multicolumn{2}{|c|}{ ISO punching shear method } \\
\hline & & & & Equation (17a) & Equation (17b) & Equation (18a) & Equation (18b) \\
\hline $\begin{array}{l}q_{\text {peak,calculated }} l \\
\quad q_{\text {peak,measured }} \\
\text { Number of tests } \\
\text { Minimum } \\
\text { Maximum } \\
\text { Mean } \\
\sigma \\
\theta^{*}: \text { degrees }^{\mathrm{a}} \\
\text { CoV: } \% \\
N_{\text {c,calculated }} / \\
N_{\text {c,measured }} \\
\text { Number of tests }{ }^{\text {b }} \\
\text { Minimum } \\
\text { Maximum } \\
\text { Mean } \\
\sigma \\
\theta^{*}: \text { degrees } \\
\text { CoV: \% } \\
d_{\text {punch,calculated }} / \\
d_{\text {punch,measured }} \\
\text { Number of tests } \\
\text { Minimum } \\
\text { Maximum } \\
\text { Mean } \\
\sigma \\
\theta^{*}: \text { degrees } \\
\text { CoV: } \%\end{array}$ & $\begin{array}{l}54 \\
0 \cdot 44 \\
0 \cdot 97 \\
0 \cdot 69 \\
0 \cdot 11 \\
-24 \cdot 47 \\
16 \cdot 49\end{array}$ & $\begin{array}{l}54 \\
0 \cdot 64 \\
1 \cdot 10 \\
0 \cdot 89 \\
0 \cdot 10 \\
-19 \cdot 55 \\
11 \cdot 65\end{array}$ & $\begin{array}{l}54 \\
0 \cdot 67 \\
2 \cdot 24 \\
1 \cdot 06 \\
0 \cdot 39 \\
2 \cdot 71 \\
36 \cdot 54\end{array}$ & \begin{tabular}{|l}
71 \\
$0 \cdot 07$ \\
$0 \cdot 53$ \\
$0 \cdot 29$ \\
$0 \cdot 10$ \\
$-13 \cdot 18$ \\
$35 \cdot 89$ \\
\\
\\
54 \\
$0 \cdot 30$ \\
$0 \cdot 60$ \\
$0 \cdot 45$ \\
$0 \cdot 07$ \\
$-15 \cdot 32$ \\
$15 \cdot 66$ \\
\\
\\
36 \\
$0 \cdot 49$ \\
$4 \cdot 54$ \\
$1 \cdot 05$ \\
$0 \cdot 75$ \\
$-58 \cdot 07$ \\
$71 \cdot 96$
\end{tabular} & $\begin{array}{l}71 \\
0 \cdot 34 \\
0 \cdot 75 \\
0 \cdot 58 \\
0 \cdot 09 \\
-8 \cdot 93 \\
15 \cdot 77 \\
\\
\\
54 \\
0 \cdot 30 \\
0 \cdot 60 \\
0 \cdot 45 \\
0 \cdot 07 \\
-15 \cdot 32 \\
15 \cdot 66 \\
\\
62 \\
0 \cdot 74 \\
27 \cdot 30 \\
2 \cdot 50 \\
3 \cdot 90 \\
-79 \cdot 83 \\
155 \cdot 89\end{array}$ & \begin{tabular}{|l}
71 \\
$0 \cdot 33$ \\
$0 \cdot 65$ \\
$0 \cdot 44$ \\
$0 \cdot 06$ \\
$2 \cdot 30$ \\
$14 \cdot 13$ \\
\\
\\
54 \\
$0 \cdot 30$ \\
$0 \cdot 60$ \\
$0 \cdot 45$ \\
$0 \cdot 07$ \\
$-15 \cdot 32$ \\
$15 \cdot 66$ \\
\\
\\
56 \\
$0 \cdot 61$ \\
$10 \cdot 56$ \\
$1 \cdot 64$ \\
$1 \cdot 56$ \\
$-69 \cdot 49$ \\
$95 \cdot 54$
\end{tabular} & $\begin{array}{l}71 \\
0 \cdot 48 \\
0 \cdot 79 \\
0 \cdot 59 \\
0 \cdot 07 \\
-3 \cdot 47 \\
12 \cdot 19 \\
\\
\\
54 \\
0 \cdot 30 \\
0 \cdot 60 \\
0 \cdot 45 \\
0 \cdot 07 \\
-15 \cdot 32 \\
15 \cdot 66 \\
\\
\\
62 \\
0 \cdot 81 \\
24 \cdot 75 \\
2 \cdot 45 \\
3 \cdot 60 \\
-78 \cdot 92 \\
146 \cdot 95\end{array}$ \\
\hline
\end{tabular}

${ }^{\text {a Skew angle }} \theta^{*}$ is the arctangent of the gradient of the linear regression line (see Fig. 6)

${ }^{\mathrm{b}}$ Only 54 tests available for $N_{\mathrm{c}}$ comparison (see Table 1 in supplementary data)

${ }^{\mathrm{c}}$ In total 62 tests have $d_{\text {punch }}$ values (see Table 1 in supplementary data). This row reflects the number of punch-through potential predicted from each method

worsening with increasing $H_{\mathrm{s}} / D . N_{\mathrm{c}}$ should increase with $H_{\mathrm{S}} / D$ due to the larger entrapped sand plug and this bias is largely alleviated in the Lee et al. method because the composite footing and sand plug is accounted for explicitly. However, a certain amount of skew remains because the small-strain FE analyses, on which the $N_{\mathrm{c}}$ factors were based, did not account for the drag-down of softer nearsurface sediments or strain softening. The large-deformation analyses performed by $\mathrm{Hu}$ et al. (2014b) accounted for both of these effects, resulting in better predictions of $N_{\mathrm{c}}$ across the full range of $H_{\mathrm{s}} / D$.

Finally, the punch-through distances measured in the centrifuge tests were compared with the predicted values. Although 62 tests were predicted to experience punchthrough failure based on the ISO load spread method, this is considered a coincidence as significant under-predictions of $q_{\text {peak }}$ and $N_{\mathrm{c}}$ were observed in Fig. 5 and in the supplementary data. In addition, large scatter and skews are reflected, with a $\mathrm{CoV}$ of $155 \cdot 9 \%$ and a skew angle of $-79.83^{\circ}$. The situation was not improved for the ISO punching shear method, with a mean of 2.45 and corresponding CoV of $147 \%$. The Teh method could only capture punch-through for 32 out of the 62 tests. Significant scatter was indicated by a $\mathrm{CoV}$ of $35.5 \%$, while the minimum discrepancy of the punch-through distance was $\sim 50 \%$. The Lee et al. method performs reasonably well, but certain cases remain that produce significant overestimations of the punch-through distance. Due to more accurate predictions of both $q_{\text {peak }}$ and $N_{\mathrm{c}}$, the $\mathrm{Hu}$ et al. method predicts the majority of the punch-through cases (54 in total). The estimated punch-through distances are within $\pm 20 \%$ for the majority of the cases, and the skew is the smallest of all the methods at $2 \cdot 71^{\circ}$.

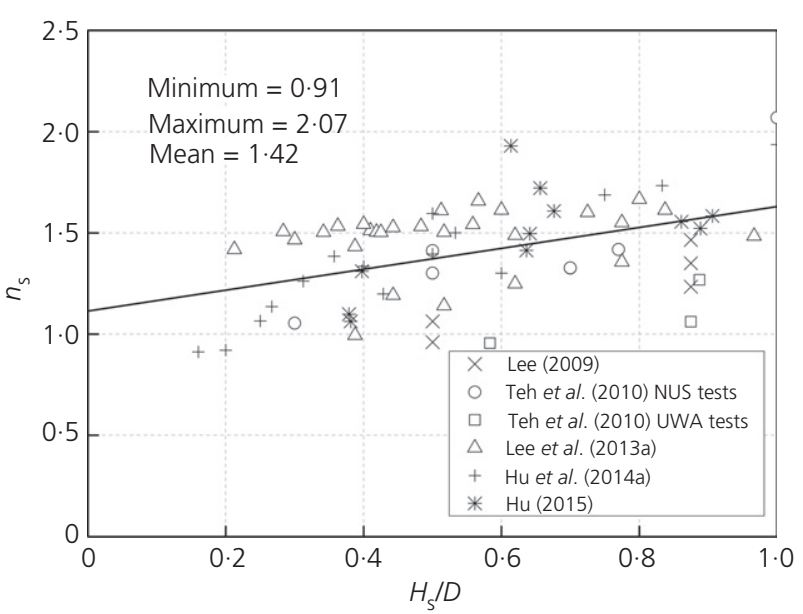

Fig. 7. Back-calculated $n_{\mathrm{s}}$ for the ISO load spread method to equal the experimentally measured $q_{\text {peak }}$ (the additional surcharge of equation (17b) is considered); the legend references the experimental database

\section{CONCLUSIONS}

This article has assessed the performance of the ISO guideline and three new alternative methods for calculating the full resistance-penetration of a spudcan into sand overlying clay. The ISO method is shown to provide worryingly inaccurate predictions for a database of 71 tests. The Teh method shows skew in the $q_{\text {peak }}$ and $N_{\mathrm{c}}$ predictions with respect to $H_{\mathrm{s}} / D$. In certain cases, this results in the method erroneously indicating no potential for punch-through 
failure. Although the Lee et al. method shows better performance overall, there is a certain amount of skew in the predictions with respect to $H_{\mathrm{s}} / D$ and, often, $q_{\text {peak }}$ is well predicted while $q_{\text {clay }}$ is poorly predicted or vice versa. The $\mathrm{Hu}$ et al. method shows the least skew with $H_{\mathrm{s}} / D$, resulting in better predictions of $q_{\text {peak }}, N_{\mathrm{c}}$ and thus $d_{\text {punch. }}$. The constructed penetration resistance profiles, which capture the distinctive aspects of a typical spudcan penetration resistance profile, are comparable with those obtained experimentally. The findings are valid within the range of experiments and simulations investigated here. Although the method has been tested on a comprehensive set of centrifuge tests, additional validation against field data would enhance confidence in its application.

\section{ACKNOWLEDGEMENTS}

This work forms part of the activities of the Centre for Offshore Foundation Systems (COFS), which is supported by the Lloyd's Register Foundation as a Centre of Excellence and currently forms one of the primary nodes of the Australian Research Council (ARC) Centre of Excellence for Geotechnical Science and Engineering. Lloyd's Register Foundation invests in science, engineering, and technology for public benefit, worldwide. This project received additional support from the Australia-China Natural Gas Technological Partnership Fund and the ARC Discovery program (DP1096764).

\section{REFERENCES}

Baglioni, V. P., Chow, G. S. \& Endley, S. N. (1982). Jack-up foundation stability in stratified soil profiles. Proc. 14th Offshore Technology Conf., Houston, TX, OTC 4409.

Craig, W. H. \& Chua, K. (1990). Deep penetration of spud-can foundation on sand and clay. Géotechnique 40, No. 4, 541-556.
Hossain, M. S., Randolph, M. F., Hu, Y. \& White, D. J. (2006). Cavity stability and bearing capacity of spudcan foundations on clay. Proc. Offshore Technology Conf., Houston, TX, OTC 17770.

Houlsby, G. T. \& Martin, C. M. (2003). Undrained bearing capacity factors for conical footings on clay. Géotechnique 53, No. 5, $513-520$.

Hu, P. (2015). Predicting punch-through failure of a spudcan on sand overlying clay. $\mathrm{PhD}$ thesis, University of Western Australia, Perth.

Hu, P., Stanier, S. A., Cassidy, M. J. \& Wang, D. (2014a). Predicting peak resistance of spudcan penetrating sand overlying clay. J. Geotech. Geoenviron. Engng 140, No. 2, 04013009.

Hu, P., Wang, D., Cassidy, M. J. \& Stanier, S. A. (2014b). Predicting the resistance profile of a spudcan penetrating sand overlying clay. Can. Geotech. J. 51, No. 10, 1151-1164.

ISO (International Organization for Standardization) (2012). ISO 19905-1: Petroleum and natural gas industries: site-specific assessment of mobile offshore unit. 1: jack-ups. Geneva: ISO/ FDIS.

Lee, K. K. (2009). Investigation of potential spudcan punch-through failure on sand overlying clay soils. $\mathrm{PhD}$ thesis, University of Western Australia, Perth.

Lee, K. K., Cassidy, M. J. \& Randolph, M. F. (2013a). Bearing capacity on sand overlying clay soils: experimental and finite element investigation of potential punch-through failure. Géotechnique 63, No. 15, 1271-1284.

Lee, K. K., Randolph, M. F. \& Cassidy, M. J. (2013b). Bearing capacity on sand overlying clay soils: a simplified conceptual model. Géotechnique 63, No. 15, 1285-1297.

Teh, K. L. (2007). Punch-through of spudcan foundation in sand overlying clay. $\mathrm{PhD}$ thesis, National University of Singapore, Singapore.

Teh, K. L., Cassidy, M. J., Leung, C. F., Chow, Y. K., Randolph, M. F. \& Quah, M. (2008). Revealing the bearing capacity mechanisms of a penetrating spudcan through sand overlying clay. Géotechnique 58, No. 10, 793-804.

Teh, K. L., Leung, C. F., Chow, Y. K. \& Cassidy, M. J. (2010). Centrifuge model study of spudcan penetration in sand overlying clay. Géotechnique 60, No. 11, 825-842. 